\section{Summary of: The signs and symptoms of tooth wear in a referred group of patients}

\author{
B. El Wazani, ${ }^{1}$ M. N. Dodd ${ }^{2}$ and A. Milosevic ${ }^{3}$
}

\section{FULL PAPER DETAILS}

${ }^{1}$ Clinical Teacher in Restorative Dentistry, Department of Clinical Dental Sciences, ${ }^{2}$ Senior House Officer in

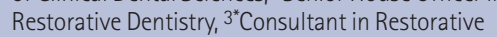
Dentistry and Honorary Senior Lecturer, Department of Restorative Dentistry, Liverpool University Denta Hospital, Pembroke Place, L3 5PS ${ }^{*}$ Correspondence to: Alexander Milosevic Email:Alexander.milosevic@rlbuht.nhs.uk Refereed Paper

Accepted 12 June 2012

DOI: $10.1038 /$ sj.bdj.2012.840

${ }^{\circ}$ British Dental Journal 2012; 213: E10

\begin{abstract}
Aim To determine the prevalence of signs and symptoms in a group of tooth wear patients referred to a hospital-based consultant clinic. Method The clinical records of 290 patients referred to the Liverpool University Dental Hospital for tooth wear were reviewed retrospectively. A systematic sampling technique was used to select every alternate patient held on the consultant database. Results There were significantly more males than females in a ratio of 2.3:1. Significantly more males (56\%) presented with severe tooth wear compared with females (31\%) $(p<0.001)$. Aesthetic concerns were the most prevalent presenting complaint (59\%) and sensitivity was the second most common presenting complaint (40\%). Functional problems and pain were less prevalent at $17 \%$ and $14 \%$ respectively. Subjects who had lost posterior support had more severe wear and more worn anterior teeth, which was statistically significant $(p=0.001)$. The proportion of subjects with undiagnosed apical pathology on worn teeth was 13\%. Conclusions Tooth wear predominated in males in this study. Patient dissatisfaction with appearance is the most common complaint and endodontic signs and symptoms are low in prevalence. Contrary to previous studies, lack of posterior support resulted in greater severity of wear, therefore restoring support is recommended.
\end{abstract}

\section{EDITOR'S SUMMARY}

Tooth wear, tooth wear everywhere but what do patients think?

Tooth wear really has come to the fore recently as a big problem to be tackled. It feels as if it is indeed 'everywhere' - seminars, conference topics, in the dental press. It has been a frequent theme on the pages of this journal, featuring in recent editorials, a series and many research articles. It is not only because we are living longer that tooth wear is a growing problem, it is also increasingly prevalent in younger generations due to erosion from acidic food and drink which, perhaps unfairly, serves to heighten its importance.

Knowing what drives patients to seek dental treatment can help with the delivery of appropriate care. Until now, there have been small-scale studies and a general feeling about why tooth wear patients seek out care and but this research paper provides retrospective, observational evidence about the signs and symptoms on a larger scale. The results are perhaps mostly unsurprising. Generally the findings back-up dentists' intuitive feel regarding the motivations of tooth wear patients ie that appearance is the main driver for treatment rather than functional problems. Sensitivity was found to be the second most common complaint; function and pain falling low on the list of symptoms. It is useful to have confirmation of the anecdotal evidence by this study of 290 subjects.

The authors also found that the number of males referred with tooth wear was over twice as high as the number of females. They put this down to the greater masticatory force males are able to generate and possible causes such as the difference in stress levels and diet. In males, attrition is a more single common factor for tooth wear whereas for women erosion is the commonest. This evidence regarding the tooth wear differences between genders should help dentists to further understand the signs of tooth wear and advise their patients appropriately regarding preventive care.

Tapping into a person's motivation can make preventive measures more effective. In the case of tooth wear, for the majority of patients, this study tells us appearance is key.

The full paper can be accessed from the $B D J$ website (www.bdj.co.uk), under 'Research' in the table of contents for Volume 213 issue 6.

Ruth Doherty Managing Editor

DOI: 10.1038/sj.bdj.2012.861 


\section{TO ACCESS THE BDJ WEBSITE TO READ THE FULL PAPER:}

- BDA Members should go to www.bda.org.

- Click the 'login' button on the right-hand side and enter your BDA login details.

- Once you have logged in click the 'BDJ' tab to transfer to the BDJ website with full access.

IF YOUR LOGIN DETAILS DO NOT WORK:

- Get a password reminder: go to www.bda.org, click the login button on the right-hand side and then click the forgotten password link.

- Use a recommended browser: we recommend Microsoft Internet Explorer or Mozilla Firefox.

- Ensure that the security settings on your browser are set to recommended levels.

IF YOU HAVE NOT YET SIGNED UP TO USE THE BDA WEBSITE:

- Go to www.bda.org/getstarted for information on how to start using the BDA website.
IN BRIEF

- Reports that males tend to present to dentists with a more advanced stage of tooth wear than females.

- Suggests appearance is the main driver for treatment rather than functional problems.

- Highlights that, somewhat surprisingly, severely worn teeth have a low prevalence of apical pathology.

- Stresses that examining for and monitoring tooth wear are increasingly important in patient management.

\section{COMMENTARY}

In these days of evidence-based dentistry it is refreshing to see an observational study, conducted retrospectively by practising clinicians, upon those attending a consultant led service for management of their tooth wear. I am sure that its findings will be useful in underpinning accepted, though evidence-sparse, preventive and restorative treatments in this field. In these days of austerity it remains important not only to clinically manage patients but also to collect as much relevant data from them so that future clinical service is developed upon evidence. This paper achieves this well. The authors are careful to state that the toothwear prevalence figures they quote are not comparable to National Survey's as the studies sample population is taken from a preselected group of individuals with toothwear. Interestingly a self assessment of oral function is included - clearly of importance as functional changes may be potential drivers to seek treatment and advice. Overwhelmingly, however, it was not function or dental sensitivity but deterioration in appearance that stimulated the patients to seek help. The relative lack of sensitivity is neatly accounted for by the authors as the successful culmination of natural protective physiological mechanisms that keep pace with the toothwear. Unlike other previous studies it is reassuring that the findings of this work confirm what many dentists intuitively believe, that lack of posterior support results both in the presence of anterior toothwear of a severity in proportion to the degree of posterior tooth loss. This underpins the conventional wisdom of replacing posterior support to prevent further wear. Of course tooth wear should not be regarded solely as a mechanical phenomenon and this is emphasised by the author's discussion of exacerbating acid sources. In the younger patient these were mostly dietary (extrinsic) whereas in older patients such acids arose intrinsically, perhaps from the ageing process and underlying medical conditions. This highlights the need to always obtain a thorough history when managing toothwear. Good though this study is, it will be interesting in future years to see how it is regarded by those formulating evidence-based reviews.

\section{R G Chadwick}

Clinical Senior Lecturer and

Hon Consultant in Restorative Dentistry The Dental School

Dundee

\section{AUTHOR QUESTIONS AND ANSWERS}

1. Why did you undertake this research? Few studies have assessed patients' complaints regarding worn dentition. Referrals to secondary care regarding tooth wear appear to be on the increase. The authors felt better understanding of patients' needs and concerns would improve patient outcomes. Furthermore, the predominant presenting complaint was anecdotally thought to be poor aesthetics but without the evidence.

The first authors were in SHO training posts and wanted experience in research methods. This was a relatively straightforward study that gave them the opportunity to handle data, set up a database and analyse data using SPSS. This was very useful as part of their postgraduate training.

2. What would you like to do next in this area to follow on from this work?

Determination of treatment outcomes using various restorative materials and techniques is a natural progression for this clinical study. It would be important to identify simple treatment measures that can be effectively provided in primary care to reduce the cost burden to the state as secondary care is deemed expensive. 